\title{
Comparison of new mathematics teaching methods with traditional method
}

\begin{abstract}
The aim of this paper is to compare the mathematics teaching methods, and study their consequences on mathematics learning. Numerous studies have shown that students experience mathematics anxiety which is a feeling of tension and fear that interfere with math learning. This may be attributed to the applied teaching methods in the classrooms. The three major teaching methods are: traditional, problem-solving, and discovery learning. Traditional teaching method is a teacher-centered instruction, while problem-solving method is a as teacher and student-centered which is based upon how teacher uses the four steps of problemsolving methods in teaching Mathematics. In discovery learning method, teacher plays the role of facilitator through involving students in varied activities associated with the discovery and construction of the knowledge. The qualitative case study method was considered more feasible and appropriate to meet the aim of this study. Data were collected using observation and semi-structured interviews with teachers in the secondary schools in Malaysia. It was observed that traditional, problem solving and discovery learning methods were practiced by the teachers. The findings reveal that students are more successful when systematic problem solving method based on Polya's approach is incorporated into discovery learning. Consequently, there should be more emphasis on teaching methods which include less lecture, more student-centered classes and more discussion. The findings suggest that problem solving and discovery methods not only contribute to better mathematics learning but also enhance students' creativity to cope with life challenges.
\end{abstract}

Keyword: Teaching methods; Discovery learning; Problem solving; Traditional methods 